\title{
Response of Melon Powdery Mildew to a Biocontrol Agent Bacillus velezensis M10 and Paraffin Oil
}

\author{
Munhaeng Lee ${ }^{1}$ and Sang Koo Park ${ }^{2 *}$ \\ ${ }^{1}$ Fruit-Vegetables Research Institute, Chungcheongnam-do ARES, Buyeo, 33119, South Korea \\ ${ }^{2}$ Food Safety Management Division, Regional Korea Food and Drug Administration, Seoul, South Korea \\ *For correspondence: rokmc3588@korea.kr \\ Received 13January 2021; Accepted 06 March 2021; Published 16 April 2021
}

\begin{abstract}
The powdery mildew caused by air borne pathogen (Podosphaera fusca) is an important disease of cucurbits including melon (Cucumis melo L.) plants. Three antagonistic bacterial strains (M4, M10 and M11); isolated from the melon plants were tested for antagonistic activity against $P$. fusca and soil-borne pathogens of melon plants (Monosporascus cannonballus, Fusarium oxysporum $f$. spp. melonis, F. solani and Phomopsis spp.). All the three strains were identified as Bacillus velezensis based on sequence analysis of gyrase subunit A (gyrA) gene sequence. The bacterial strains showed significant antagonistic activity against soil and air borne pathogenic fungi. Among all strains, M10 showed a broad spectrum of mycelial growth inhibition against phytopathogenic fungi. The tested culture broth did not affect the pollen fertilization, flowering, fruit rot occurrence and fruit set development during blooming and cultivation season of the melon plants. The M10 culture broth stored for 3 and 6 months displayed biocontrol efficiency of 73.2 and $72.3 \%$, respectively. Application of mixed solution of M10 culture broth + paraffin oil strongly suppressed the incidence and spread of powdery mildew. These results suggested that the combination of paraffin oil and B. velezensis M10 culture broth is an ecofriendly approach and possess strong biocontrol potential against melon powdery mildew and can also be used as antifungal agents for several plant pathogens. (C) 2021 Friends Science Publishers
\end{abstract}

Keywords: Biocontrol; Melon; Powdery mildew; Paraffin oil

\section{Introduction}

The powdery mildew caused by air-borne pathogen, Podosphaera fusca (Fr.) Braun \& Shishkoff (syn. Sphaerotheca fuliginea, $P$. xanthii) is very persistent disease in cucurbits including melon plants grown in the greenhouse. The powdery mildew causal organism prefers warm and dry conditions for the proliferation and growth of spores and is easily visible on leaf surface of melon plants (Bandamaravuri et al. 2020). Globally, 28 races of $P$. fusca have been reported and eight of these races are present in Korea (Kim et al. 2015, 2016).

The protected cultivation (tunnel faming or greenhouses) area for fruit and vegetables in Korea is 38,623 ha and of this area, melon is cultivated on 1,456 ha in the greenhouse. In Korea, the total certified area for organic agricultural production is 80,100 ha yielding $496,400 \mathrm{M} / \mathrm{T}$ of organic produce (MAFRA 2017). On the other hand, the world's organic farming areas estimated to increase by $12 \%$ up to 57.8 million ha in 2016 compared to 2015 (Jeong et al. 2018). These trend shows that the demand and purchase of environment-friendly agricultural produce are steadily increasing. However, the organic agricultural products are not easy to cultivate and produce without chemical spraying due high incidence of pests and disease attack such as powdery mildew. In this scenario, use of beneficial plant microbes (biocontrol) offers an effective alternative to chemical pest control for organic crop production. The beneficial bacteria live as well adapted nonphytopathogens in rhizosphere, soil, water, and in or on surface of plants tissues. These bacteria (antagonists) have 2 types of functional characterizations on plants, among these one is to promote plants growth through colonization of rhizosphere by plant growth promoting rhizobacteria (PGPR) and production of various phytohormones, such as auxin and gibberelines (Meng et al. 2016; Rehman et al. 2018), the other is to protect plants from the diseases, and increasing plant tolerance to environmental stresses (Meng et al. 2012; Sharf et al. 2021).

Microbial agents using antagonistic bacteria are regarded as the alternative solution to chemical control, which protect the plants from pests, diseases (e.g., powdery mildew of cucurbits) and hazardous effects of the fungicide application (Rur et al. 2018). For instance, Romero et al. (2007a) elucidated Bacillus subtilis strains producing three lipopeptides antibiotics which showed inhibitory activity on conidia germination and development of $P$. fusca, powdery mildew pathogen on melon leaves. The lipopeptides 
produced by $B$. subtilis antagonistically affected the sterol content in target pathogen which results in membrane damage due to disruption of sterol buffering function in maintaining plasma membrane fluidity. Thus, the low sterol concentration of conidia of $P$. fusca could be due to its higher susceptibility lipopeptides antibiotics produced by $B$. subtilis (Loeffler et al. 1992; Avis and Belanger 2002). Likewise, Pseudomonas fluorescens application in tomato under control and field conditions effectively suppressed and limited the population of damping off, stem rot, bacterial wilt and leaf blight diseases caused by several pathogens such as Pythium ultimum, Sclerotium rolfsii, Ralstonia solanacearum and Alternaris solani, respectively (Thiibhuvanamala et al. 1999; Whistler et al. 2000; Hegde and Anahosur 2001) and also enhanced the plant growth, biomass production and yield than untreated control plants (Manoranjiham and Prakasam 1999; Khan and Akram 2000). Although biocontrol agents have strong antifungal and antibacterial activity, the mixture of two or more species between antagonistic bacteria and fungi may or may not prove effective in disease suppression. Thus, the prerequisites for stabilization of species and strain mixture is important for the compatibility of the co inoculated microbes (Boer et al. 1997; Raupach and Kloepper 1998).

The present study aimed to evaluate the antagonistic activity of $B$. velezensis (M10) culture broth against $P$. fudca and other soil-borne pathogens of melon plants. The M10 culture broth concentration and storage duration were optimized and tested alone or in combination with paraffin oil for inducing resistance against powdery mildew and improving flowering and fruit setting in melon plants under greenhouse conditions. The specific objective of this study was to develop eco-friendly plant protectants as an alternative to pesticides for control of melon powdery mildew.

\section{Materials and Methods}

\section{Isolation, identification and culture preparation of antagonistic bacteria}

In this study, antagonistic bacteria, Bacillus spp. were isolated from melon cultivated in Buyeo, Chungnam province, Korea in 2018. The genomic DNA of three strains was extracted using Accuprep DNA extraction kit (Bioneer, Daejeon, Korea). The gyrase subunit A (gyrA) gene were amplified by PCR using $p$-gyrA-f and $p$-gyrA-r primer (Roberts et al. 1994). DNA sequencing was performed at Macrogen (Seoul, Korea) using an automated DNA analyzer system (PRISM 3730XL DNA Analyzer, Applied Biosystems, U.S.A.). The sequences were edited using MEGA v. 5.0 (Tamura et al. 2011). Alignments were performed using the default settings of MAFFT v. 7 (Katoh and Standley 2013). Neighbor-joining (NJ) trees were constructed with MEGA 5 using Kimura 2- parameter model and 1000 bootstrap replicates (Kimura 1980).

For mass production of antagonistic bacteria, first, bacteria cells were streaked on Yeast Extract Peptone Dextrose (YPD) agar (Difco ${ }^{\mathrm{TM}}$ ) medium, then the plates were incubated at $30 \pm 1{ }^{\circ} \mathrm{C}$ for $48 \mathrm{~h}$. Later, the cell seed for mass growth of visible cells was incubated on YPD broth for $48 \mathrm{~h}$. Finally, the $10 \mathrm{~mL}$ inoculum of cell seeds were transferred into 2L Erlenmeyer flasks containing 1 L Soy Peptone Yeast broth. Therefore, the flasks were cultured at $120 \mathrm{rpm}$ for $72 \mathrm{~h}\left(35 \pm 1^{\circ} \mathrm{C}\right)$ in shaking incubator (Hanbaek Scientific, Co.) The composition of SPY broth is as follows; soy peptone $20 \mathrm{~g}$, yeast extract $20 \mathrm{~g}, \mathrm{CaCl}_{2} \mathrm{H}_{2} \mathrm{O} 0.8 \mathrm{~g}$, $\mathrm{K}_{2} \mathrm{HPO}_{4}$ dibasic $1.0 \mathrm{~g}, \mathrm{MgSO}_{4}$ anhydrous $1.0 \mathrm{~g}, \mathrm{MnSO}_{4} 0.2$ $\mathrm{g}$, glucose $15 \mathrm{~g}$ and distilled water $1 \mathrm{~L}$. Bacterial cultures obtained from shaking incubation were also used by storing in the refrigerator.

\section{Antifungal Activity}

To determine the antifungal activity, cells of $B$. velezensis M10 and the mycelial plug $(5 \mathrm{~mm})$ of the pathogens such as Monosporascus cannonballus (KACC No. 42093), Didymella bryoniae (KACC No. 40937), Fusarium oxysporum f. spp. melonis (KACC No. 47669), Fusarium solani as well as Phomopsis spp. were inoculated at the edges of the YPD agar medium on opposite sides followed by incubation of cultures in the incubator at $27 \pm 1^{\circ} \mathrm{C}$ for 10 to 15 days. These Pathogen strains were obtained from the National Agrobiodiversity Center of the National Institute of Agricultural Science, Korea. The formation of mycelial inhibition zones and degree of mycelial growth was investigated.

\section{Dilution of the culture broth}

In March 2019, melon seeds (variety: Earl's talent) were sown in a pot having a diameter of $5 \mathrm{~cm}$. Four-week-old melon seedlings were transplanted in the soil of the greenhouse on April 16. The powdery mildew of melon plants occurred naturally without artificial inoculation. When the lesion of powdery mildew started to appear on $12^{\text {th }} \sim 13^{\text {th }}$ leaf, the bacterial culture broth; diluted to 100, 300 and 400fold were treated to whole melon plants having uniform and constant growth conditions. Thus, the bacterial culture broths were applied three times at 5-day intervals and five leaves from the $12^{\text {th }}$ to the $16^{\text {th }}$ were used to determine the disease incidence and biocontrol activity. Disease incidence and biocontrol activity on the melon leaves were measured 7 days after final treatments of the culture broths.

The disease index of melon powdery mildew for control and infected plants was measured according to a disease rating scale from 0 to 4 (Table 1) using the formula:

\footnotetext{
Disease Index $(\%)=[($ Low $\times 1)+($ Moderate $\times 2)+($ High $\times 3)$ $+($ Severe $\times 4) /$ No. of investigated leaves $\times 4] \times 100$

Control Value $(\%)=(1-($ culture broth treatments $)) /$ Nontreatments))/No.
} 


\section{Culture broth toxic assay on flowers}

Melon powdery mildew occurs throughout the growing season from seedlings to harvest. In blooming period, due to high humidity in the greenhouse and high moisture in the flowers trigger the flower infections by pathogens at blooming, pollen fertilization and initiation of fruit setting. Therefore, at times fruit rot occurred at maturity. The culture broth of diluted 300-fold were treated into flowers on May 24 and 27 after transplanted on May 1, 2019. We investigated the inhibitory effects of B. velezensis M10 cultures on incidences and development of melon powdery mildew in flowers, fertilization, fruits set and fruit rot.

\section{Effect of long-term storage of the culture}

The persistence of antifungal activity of culture broth against melon powdery mildew was examined through long-term storage of M10 culture broth. The bacterial culture broth was stored in the refrigerator $\left(4 \pm 1^{\circ} \mathrm{C}\right.$ for 3,6 and 12 months. After transplanted on May 30, 2019, plants were treated three times with culture (diluted 300-fold) at five days interval on June 28, July 3 and 8 . The incidence of powdery mildew and the control value of culture broth were recorded one week after the final treatments.

\section{Effect of supplement to improve biocontrol efficiency}

Paraffin oil $(0.25 \%)$ were used as a supplement to aid in maintaining stability of the antifungal components in the culture and to adequately enhance the antifungal activity on infected melon leaves. The antagonistic bacterial culture broth was diluted to 300-fold. The seedlings of melon were transplanted in the soil of the greenhouse on July 30, 2019. The mixture of bacterial culture and a supplement were treated on the leaves by three times at five days interval. To evaluate the control effectiveness, five leaves from the $12^{\text {th }}$ to the $16^{\text {th }}$ were collected and investigated about the disease severity and biocontrol effect of powdery mildew after one week of the final treatments.

\section{Statistical analysis}

The statistical software, SAS (SAS Institute Inc., Cary, NC, USA), was used to analyze the mean and the standard error of the experimental results. The significance of the experimental data obtained for each analytical item was analyzed by using SPSS 23.0 version. The significance was tested at the level of $P<0.05$ by performing Duncan's Multiple Range Test.

\section{Results}

\section{Identification and antifungal activity}

On basis of sequence analysis of gyrase subunit, A (gyrA) gene, three strains (M4, M10 and M11) formed monophyletic group and revealed $99.8 \%$ similarity with type species (NRRL B-41580) of B. velezensis. Therefore, three isolates were identified as B. velezensis strains (Fig. 1). The three strains of $B$. velezensis showed inhibition for the mycelial growth of soil-borne pathogens of melon plants viz. M. cannonballus, F. oxysporum f. spp. Melonis, F. solani and Phomopsis spp. Among the tested strains B. velezensis M10 showed relatively strong inhibition of mycelial growth for melon plants pathogen and inhibited the mycelial growth of $M$. cannonballus, $F$. oxysporum f. spp. Melonis, $F$. solani and Phomopsis spp. by 42, 36, 30 and 33\%, respectively. Inhibition effect of M10 strain on mycelial growth of $M$. cannonballus, D. bryoniae and G. nigrescens was stronger than two Fusarium species and Phomopsis spp. (Fig. 2). Therefore, isolates M10 strain was used for further studies.

\section{Dilution response of culture broth on powdery mildew}

The leaves of melon plants grown in the greenhouse were naturally infected by melon air-borne powdery mildew pathogen, $P$. fusca. To assay control value of powdery mildew, disease incidence rate was measured according to disease severity index; indicating the ratio of the lesion area to the total leaf area (Fig. 3). Symptoms of powdery mildew started to appear from lower leaves of melon plants about 3 weeks after transplanting. In control treatments, disease incidence of leaves collected from the $12^{\text {th }}$ to the $16^{\text {th }}$ leaf of 21 melon plants had lesion area of $90.0 \%$ level. Contrary to this, disease severity on the leaves of melon plants treated with diluted 100, 300 and 400-fold culture broth showed lesion area of 24.9, 25.3 and $25.5 \%$, respectively (Table 2 and Fig. 4).

\section{Phytotoxic effect of the cultures on flowering and fruit setting}

In blooming period, high humidity in greenhouse and the water attached on flowers could be a problem in terms of poor fertilization of flowers, deformation of fruits and contamination of several parasitic fungi on fruits. In the control treatments, fruit rot occurred on 6 plants out of 63 plants (Table 3). It appeared before or after the net formation on the rind of melon. On the other hand, $B$. velezensis M10 treated plants did not inhibited the flowering, pollen fertilization and also showed $100 \%$ fruit set with no fruit rot by pollen infection (Fig. 5).

\section{Effect of long-term storage of the cultures}

The storage duration significantly influenced the culture broth efficacy. The disease incidence of powdery mildew was $80.6 \%$ in the control treatment. Control value of the cultures stored for three and six months were 73.2 and $72.3 \%$, respectively (Table 4). The control effect of the cultures not stored or stored for 3 6 months was not significant $(72.3$ to $73.5 \%)$; indicating that antifungal 


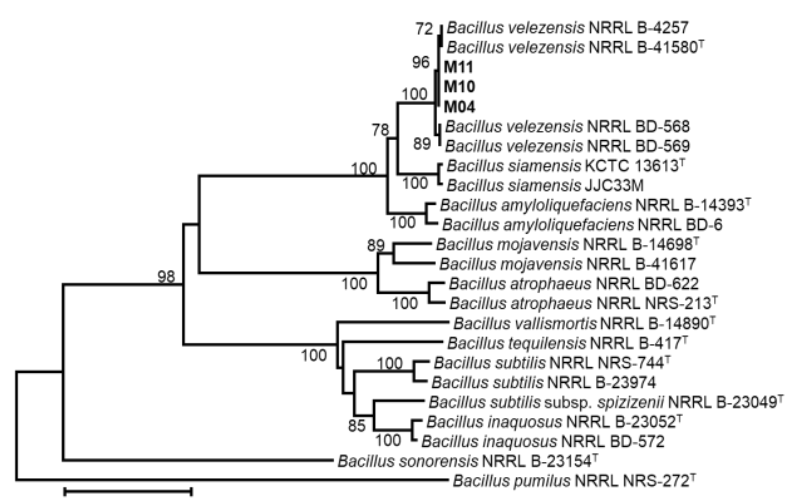

Fig. 1: Neighbor joining tree inferred from gyrase subunit A(gyrA) gene sequences of Bacillus subtilis species complex. Bootstrap scores $>70$ are presented at the nodes. The scale bar indicates the number of nucleotide substitutions per site. The selected antagonistic bacteria are indicated in bold. "T" indicates the ex-type strains

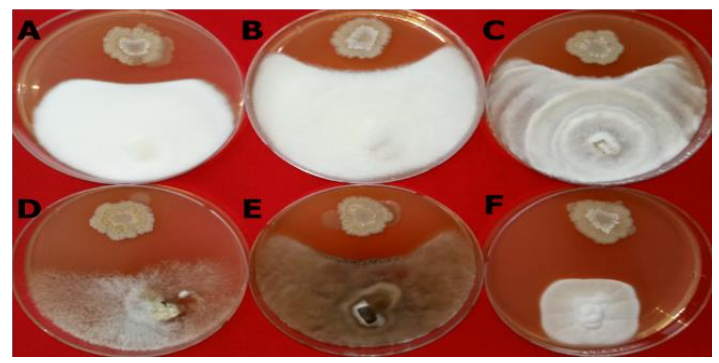

Fig. 2: Antifungal activity of B. velezensis M10 strain against major fungal pathogens causing severe disease on aerial and subterranean parts of melon plants. A) Fusarium oxysporum $f$. spp. melonis, B) F. solani, C) Phomopsis spp., D) Monosporascus cannonballus, E) Didymella bryoniae, F) Geodermatophilus nigrescens

activity of the cultures was not changed during storage period of $3 \sim 6$ months and also the functional roles for inhibition of the mycelium and colonies on melon leaves have well sustained. Meanwhile activity of the cultures stored for 12 months has reduced and showed a low control effect of $62.6 \%$ compared to other treatments.

\section{Effect of paraffin oil on M10 culture broth efficacy for bio control of Powdery Mildew}

The non-viscous culture broth is easily detached from leaves because of tiny hairs presence on the back of melon leaf. In this scenario, the antifungal components like peptides and lytic enzymes attachment for longer duration is very crucial for the biocontrol efficiency on leaves. Paraffin oil were added to the final concentration of $0.25 \%$ into the diluted 300-fold of M10 culture broth, which substantially enhanced the control value (88.5\%; Table 5). The biocontrol value of the mixed solution (Paraffin oil + culture broth) increased by $16 \%$ and strongly suppressed the mycelium growth compared to sole culture broth treatment (Table 5).
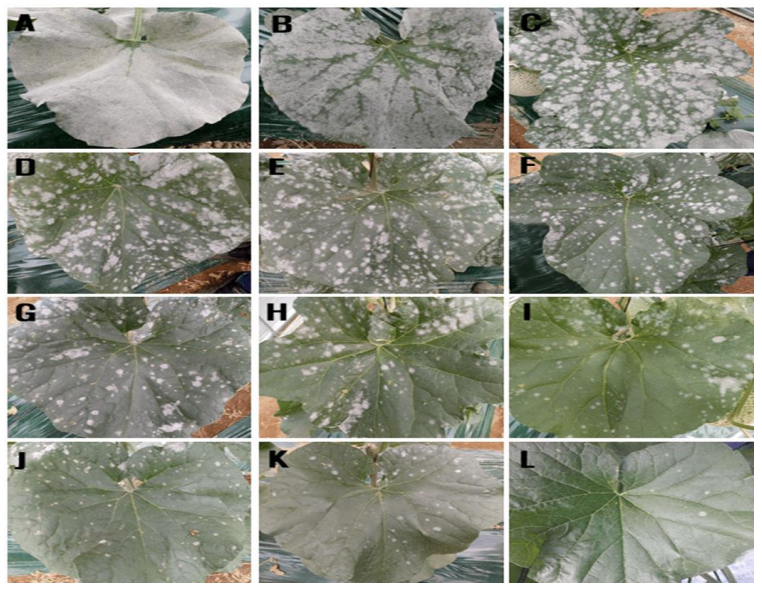

Fig. 3: The development degree of powdery mildew in melon leaf was differed into four grades the lesion index of powdery mildew indicates that $\mathbf{A} \sim \mathbf{C}$ (Index 4) lesion area; 100 80.1(\%), D F (Index 3) lesion area; 80 60.1(\%), G I (Index 2) lesion area; 60 30.1(\%), J L L (Index 1) lesion area; 30 1(\%)

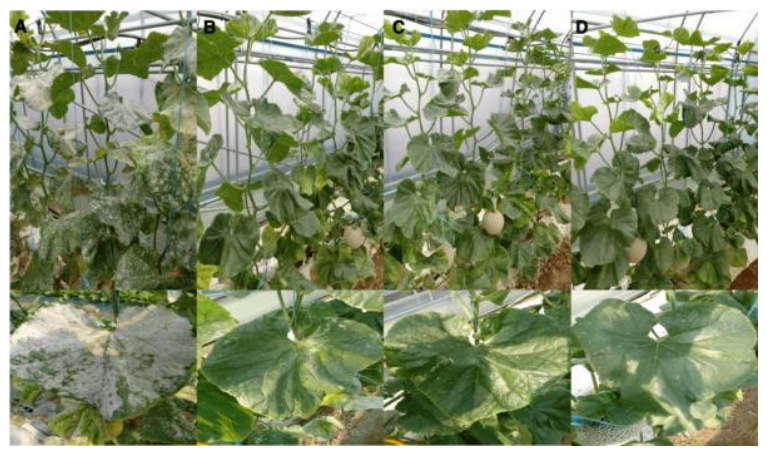

Fig. 4: Comparison of powdery mildew occurred on the leaf surface of melon plants 7 days after treatment of three times at 5day intervals. Water control (A) and the culture broth of $B$. velezensis M10 were diluted 100 (B), 300 (C) and 400 times (D)

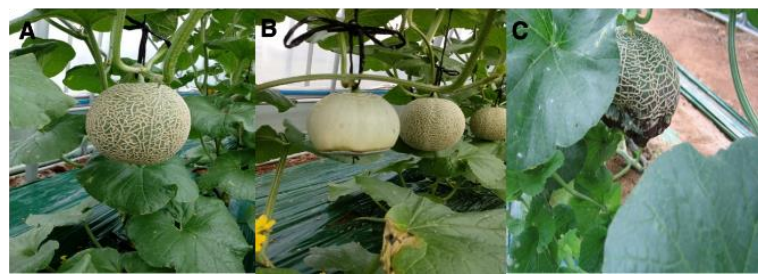

Fig. 5: Effects of the cultures of B. velezensis M10 strain on the development of blooming, fertilization and fruiting of melon plants. The diluted 300-fold culture broth (A) and water (B and $\mathbf{C}$ ) was treated two times at 3 -day intervals during blooming period

\section{Discussion}

The protected cultivation systems allow the year-round production of various fruit and vegetables. Melon powdery mildew is one of the serious diseases that cause huge yield losses of melons grown in protected cultivation systems. Bacterial strains with antagonistic activity have 
demonstrated effectiveness in biological control of powdery mildew in cucurbits (Lim et al. 2008; Rur et al. 2018). In current study, the B. velezensis M10 strain showed strong inhibition activity on mycelial growth of $P$. fusca and other major pathogens of melon plants viz., Monosporascus cannonballus, Didymella bryoniae, Fusarium oxysporum f. spp. melonis, F. solani and Phomopsis spp. The $B$. velezensis M10 strain culture broth application substantially reduced the incidence and severity of powdery mildew on melon leaves. The M10 strain treatment resulted significant reduction in the development of pathogen colonies and poor mycelium growth on the leaf tissues; which can be attributed to higher biocontrol activity of bacteria in the Genus Bacillus against powdery mildew as was observed in other crops including cucumber and mustard (Lee et al. 2013, 2016). The lipopeptide antibiotics, fengycin, surfactin and iturin (or bacillomycin) and antibiotics and secondary metabolites derived from the species of $B$. subtilis complex group inhibit mycelial growth of plant pathogen in addition to suppression of spores germination, and also reported to induce resistance response to plants against invasion and infection of plant pathogen (Pal and Gardener 2006; Romero et al. 2007b) as was observed in current study.

The cultures derived from antagonist microbe for biocontrol did not affect the development of flowers and fruiting of plants. We did not observe any harmful effect between culture broth and flowers in vitro, so physical and chemical mechanism of antibiotics in culture broth could not be involved. However, the result of rapid prior colonization of antagonistic bacteria through competitive exclusion of pathogens in flowers may be an important factor in biocontrol efficacy and disease reduction (Sorokina et al. 1999; Psol et al. 2005).

Here we observed, biocontrol value on the melon leaves were 73.2 and $72.3 \%$ for long term stored cultures (3 and 6 months), respectively, which indicate loss of antifungal activity of $B$. velezensis M10 culture broth with long term storage (12 months), suggesting that the culture broth of $B$. velezensis M10 should be used within 6 month of storage for effective biocontrol of powdery mildew in melon. Sometime bacterial antagonists have ambivalent properties as beneficial or toxic traits to plants depending on the prevailing environment (symbiotic-parasitic) in which they inhabit on each other. For instance, an antagonist $P$. orientalis used for biocontrol of fire blight disease diminished the Erwinia amylovora infestation as well as phytotoxicity in the apple (Wilson and Lindow 1993; Gerami et al. 2013; Zengerer et al. 2018); indicating the current control behaviors focusing on the limitation of the pathogen in the flower. Otherwise, the culture broth is easily detached from the melon leaves where tiny hairs being densely placed and which have physical protective functions from pests. To maintain antifungal activity for a long time on the leaf surface, effective attachment ability of the fungicidal substance in the culture broth is being absolutely required. Nakata et al. (2000) suggested that polysaccharide enhanced adhesive force of $P$. fluorescens S272 cells which might have promoted plants growth with increased antibiotic activity as was observed in present study. Ko et al. (2003) also demonstrated that sunflower oil inhibits the spore germination and the mycelial growth of Oidium neolycopersici causing powdery mildew on the leaf surface of tomato. The cooking oil mixed with egg yolk has significantly destroyed both mycelium and conidia of cucumber powdery mildew and downy mildew pathogens (Jee et al. 2009). So, the physical and directly fungicide activity of oils was generally considered as a major action point of disease control (Ohtsuka and Nakazawa 1991; Northover and Schneider 1996). Here, the Paraffin oil + culture broth treatment ceased or extensively slow down the spread of small lesion of white colonies compare to the initial occurrence on the leaves, which can be ascribed to role of paraffin oil in enhancement of adhesiveness of chemical substances. Yi et al. (2014) reported that in control of the melanose disease of citrus, when paraffin oil added to the mancozeb wettable powder solution, chemical substance were attached on the surface of fruits more than treatments of wettable powder only. Furthermore, higher powdery mildew control in present study was demonstrated by combination of culture broth and paraffin oil as paraffin oil has been reported to enhance the antifungal activity of active ingredients with higher control efficiency as it slows down the dissolution of effective ingredient within the greenhouse environment even under the presence of strong sunlight and drying; and as a result, the adhesion on plant surfaces improved the extent of control effects (Yi et al. 2014).

The most beneficial contribution of biocontrol in the world is to preserve persistently the nature and agricultural ecosystem, and to reduce environmental pollutions from chemicals poisoning that threatening food safety as well as pests. The Bacillus and Pseudomonas strains are being examined extensively for applying directly without any advese effect on agriculture and ecosystem sustainability. The bacteria of these the genus will be useful protectants for biocontrol that suppress disease incidence and spread by safely protecting economic crops from phytopathogen infections.

\section{Conclusion}

The result of present study revealed that application of $B$. velezensis M10 significantly lowered the incidence and severity of powdery mildew disease in melon plants. Paraffin oil enhances the adhesiveness and its combination with M10 culture broth further enhanced the biocontrol efficacy of $B$. velezensis M10 against $P$. fusca under greenhouse environment. Application of B. velezensis M10 + paraffin oil provides an ecofriendly and cost-effective solution for control of melon powdery mildew in various crops under greenhouse environments and can be used in integrated disease management. 


\section{Author Contributions}

Munhaeng Lee carried conducted the study. SK Park did data analysis and prepared the manuscript draft.

\section{Conflicts of Interest}

The authors delare no conflict of interests among themselves and the institutions where the work was carried out.

\section{Data Availability}

The data supporting the findings of this study are available within the article and its supplementary materials.

\section{Ehics Approval}

All procedures performed in this study were in accordance with the ethical standards of the institution at which the studies were conducted

\section{References}

Avis TJ, RR Belanger (2002). Mechanisms and means if detection of biocontrol activity of Pseudozima yeast against plant-pathogenic fungi. FEMS Yeast Res 2:5-8

Bandamaravuri KB, AK Nayak, AS Bandamaravuri, A Samad (2020). Simultaneous detection of downy mildew and powdery mildew pathogens on Cucumis sativus and other cucurbits using duplexqPCR and HRM analysis. AMB Expr 10; Article 135

Boer MD, IVD Sluis, LCV Loon, PAHM Bakker (1997). In vitro compatibility between fluorescent Pseudomonas spp. strains can increase effectivity of Fusarium with control by combinations of these strains. In: Plant Growth Promoting Rhizobacteria-Present Status and Future Prospects, $4^{\text {th }}$ edn, pp:380-382. Ogoshi A, K Kobayashi, Y Homma, F Kodama, N Kondo, S Akino (Eds.). Proc. Intl. Workshop on Plant Growth Promoting Rhizobacteria. Nakanishi Printing, Sapporo, Japan

Gerami E, N Hassanzadeh, H Abdollahi, A Ghasemi, A Heydari (2013). Evaluation of some bacterial antagonisms for biological control of fire blight disease. J Plant Pathol 95:127-134

Hegde GM, KH Anahosur (2001). Evaluation of fungitoxicants against fruit rot of chili and their effect in biochemical constituents. Karnat $J$ Agric Sci 14:836-838

Jee HJ, CK Shim, KY Ryu, JH Park, BM Lee, DH Choi, GH Ryu (2009). Control of powdery and downy mildews of cucumber by using cooking oils and yolk mixture. Plant Pathol J 2:280-285

Jeong HG, JH Sung, HJ Lee (2018). Market status and challenges of domestic and oversea eco-friendly agricultural products. K.R.E.I. Agriculture Focus. No.169. Available online at http://www.krei.re.kr. (Accessed: January 01, 2021)

Katoh K, DM Standley (2013). MAFFT multiple sequence alignment software version 7: improvements in performance and usability. Mol Biol Evol 30:772-780

Khan MR, M Akram (2000). Effects of certain antagonistic fungi and rhizobacteria on wilt disease complex of tomato caused by Meloidogyne incognita and Fusarium oxysporum f. spp. lycopersici. Nematol Mediterr 28:139-144

Kim HT, JI Park, IS Nou (2016). Identification of fungal races that cause powdery mildew in melon (Cucumis melo L.) and selection of resistant commercial melon cultivars against the identified races in Korea. J Plant Biotechnol 43:58-65
Kim HT, JI Park, T Ishikawa, M Kuzuya, M Hortii, K Yashiro, IS Nou (2015). Development of molecular marker to select resistant lines and to differentiate the related to powdery mildew in melon (Cucumis melo L.). J Plant Biotechnol 42:284-289

Kimura MA (1980). Simple method for estimating evolutionary rates of base substitutions through comparative studies of nucleotide sequences. J Mol Evol 16:111-20

Ko WH, SY Wang, TF Hsieh, PJ Ann (2003). Effects of sunflower oil on tomato powdery mildew caused by Oidium neolycopersici. $J$ Phytopathol 151:144-148

Lee SY, HY Weon, JJ Kim, JH Han (2016). Biocontrol of leaf mustard powdery mildew caused by Erysiphe cruciferum using Bacillus velezensis YP2. Kor J Pest Sci 20:369-374

Lee SY, HY Weon, JJ Kim, JH Han, WG Kim (2013). Biological control of cucumber powdery mildew by Bacillus amyloliquefaciens M27. Kor J Mycol 41:268-273

Lim TH, JS Cho, SJ Kang, IY Johnson, BJ Cha, YH Choi (2008). Effects of Streptomyces griseofuscus 200401 on melon powdery mildew in greenhouse. Plant Pathol J 24:63-66

Loeffler RST, JA Butters, DW Hollomon (1992). The sterol composition of powdery mildews. Phytochemistry 31:1561-1563

MAFRA - Ministry of Agriculture, Food and Rural Affairs (2017). Facilities vegetable greenhouse status and vegetable production. Available online at http://www.mafra.go.kr (Accessed: January 13, 2021)

Manoranjiham SK, V Prakasam (1999). Biological control of damping off disease of tomato. S Ind Hortic 47:302-303

Meng Q, H Jiang, JJ Hao (2016). Effects of Bacillus velezensis strain BAC03 in promoting plant growth. Biol Cont 98:18-26

Meng QX, HH Jiang, LE Hanson, JJ Hao (2012). Characterizing a novel strain of Bacillus amyloliquefaciens BAC03 for potential biological control application. J Appl Microbiol 113:1165-1175

Nakata K, N Harada, K Sumitomo, K Yoneda (2000). Enhancement of plant stem growth by flocculation of the antibiotic-producing bacterium, Pseudomonas fluorescens S272, on the roots. Biosci Biotechnol Biochem 64:459-465

Northover J, KE Schneider (1996). Physical modes of action of petroleum and plant oils on powdery mildews of grape-vine. Plant Dis 80:544-550

Ohtsuka N, Y Nakazawa (1991). The influence of machine oil on conidia and hyphae of cucumber powdery mildew fungus, Sphaerotheca fuliginea. Annu Phytopathol Soc 57:598-602

Pal KK, BM Gardener (2006). Biological control of plant pathogens. Plant Health Instruct 2; Article 1117-02

Psol M, E Badosa, J Cabrefiga, E Montesinos (2005). Development of a strain-specific quantitative method for monitoring Psedomonas fluorescens EPS62e, a novel biocontrol agent of fire blight. FEMS Microbiol Lett 249:343-392

Raupach G, JW Kloepper (1998). Mixtures of plant growth-promoting rhizobacteria enhance biological control of multiple cucumber pathogens. Phytopathology 88:1158-1164

Rehman A, M Farooq, M Naveed, L Ozturk, A Nawaz (2018). Pseudomonas-aided zinc application improves the productivity and biofortification of bread wheat. Crop Past Sci 69:659-672

Roberts MS, LK Nakamura, FM Cohan (1994). Bacillus mojavensis spp. nov., distinguishable from Bacillus subtilis by sexual isolation, divergence in DNA sequence, and differences in fatty acid composition. Intl J Syst Bacteriol 44:256-264

Romero D, AD Vicente, RH Rakotoaly, SE Dufore, JW Veening, E Arrebola, FM Cazorla, OP Kulpers, M Paquot, A Perez-Garcia (2007a). The iturin and fengycin fanilies of lipopeptides are key factors in antagonism of Bacillus subtilis toward Podosphera fusca. Mol Plant-Microb Interact 20:430-440

Romero D, AD Vicente, H Zeriouh, FM Cazoria, D Fernandez-Ortuno, JA Tores, A Perez-Garcia (2007b). Evaluation of biological control agents for managing cucurbit powdery mildew on greenhouse-grown melon. Plant Pathol 56:976-986

Rur M, B Rämert, M Hökeberg, RR Vetukuri, L Grenville-Briggs, E Liljeroth (2018). Screening of alternative products for integrated pest management of cucurbit powdery mildew in Sweden. Eur J Plant Pathol 150:127-138 
Sharf W, A Javaid, A Shoaib, IH Khan (2021). Induction of resistance in chili against Sclerotium rolfsii by plant-growth-promoting rhizobacteria and Anagallis arvensis. Egypt J Biol Pest Cont 31:1-11

Sorokina TA, VA Lipasova, N Andreeva, IA Khmel (1999). The use of bacterial antagonists for the biological control of Fusarium infection on the carnation plants growing in hydroponic solution. Biotekhnonohiya 15:78-82

Tamura K, D Peterson, N Peterson, G Stecher, M Nei, S Kumar (2011). MEGA5: Molecular evolutionary genetics analysis using maximum likelihood, evolutionary distance, and maximum parsimony methods. Mol Biol Evol 28:2731-2739

Thiibhuvanamala G, E Rajeswari, S Duraiswamy (1999). Biological control of stem rot of tomato caused by Sclerotium rolfsii Sacc. Madras Agric J 86:30-33
Whistler CA, VO Stockwell, JE Loper (2000). Lon protease influences antibiotic production and UV tolerance of Pseudomonas fluorescens pf-5. Appl Environ Nicrobiol 66:2718-2725

Wilson M, SE Lindow (1993). Interactions between the biological control agent Pseudomonas fluorescencs strain A506 and Erwinia amylovora in pear flowers. Phytopathology 83:117-123

Yi PH, JW Hyun, RY Hwang, KS Kim (2014). Improvement of control efficacy of mancozeb wettable powder against citrus melanose by mixing with paraffin oil. Res Plant Dis 20:196-200

Zengerer V, M Schmid, M Bieri, DC Muller, MNP RemusEmsermann, CH Ahrens, C Pelludat (2018). Pseudomonas orientalis F9: A potent antagonist against phytopathogens with phytotoxic effect in the apple flower. Front Microbiol 9; Article 145 